\title{
Recreational Reading in The Arab World: A Critical ReView of The Arab READING INDEX
}

\author{
Ahmed J Jouda \\ University of Malaya \\ ahmadjjouda@gmail.com \\ Puteri Kamilah Mohd Azanuddin \\ University of Malaya \\ puterikamilah99@gmail.com \\ Azizah Hamzah \\ University of Malaya \\ azizah@um.edu.my \\ Md Azalanshah Md Syed \\ University of Malaya \\ azalan@um.edu.my
}

\begin{abstract}
This study explores the concept and significance of recreational reading in the Arab world. Recreational reading, often termed "Reading for pleasure," (Clark \& Rumbold, 2006), "voluntary reading," (Krashen, 2004), or "independent reading," (Cullinan, 2000 ) is the reading carried out by personal choice. However, recreational reading in the Arab world rarely gets attention through comprehensive scholarly studies. Thus, this textual study also examines the context of recreational reading and the initiatives taken to enhance this activity in the Arab region.
\end{abstract}

Keywords: recreational readings, book studies, Arabs, qualitative studies

\section{INTRODUCTION}

Recreational reading reflects the reader's personal interest in books of their choosing, to be read at a time and place they please (Richardson \& Eccles, 2007; Cullinan, 2000). Pleasure reading is entirely pursued for its own sake (Apter, 1979). In an abstraction of the confines of our regular reality, it allows us to traverse in mind and body, to other fanciful realms and fictitious roles (Nell, 1988). Unlike the common notion in which the benefits of reading are isolated within their primary activity, Holden perceives reading as a genuinely creative activity that contributes toward creating general creative activities (2004). The 2006 UK's National Literacy Trust report defined reading for pleasure as a reciprocated process that 
brings the reader and the book in a dynamically interactive relationship (Crack \& Rumbold, 2006). In the words of the British Department of Culture, Media, and Sport (DCMS), "Reading is a prerequisite for almost all cultural and social activities. People cannot be active or well-informed citizens unless they can read" (2003, p.5).

The value accorded to the practice of reading foretells its great benefits. Beyond its direct benefits in the field of literacy and school achievement, reading is an essential gateway to human development, and to social and economic prosperity (Holden, 2004). Of its substantial benefits, reading stimulates the part of the brain responsible for comprehension (Berns, Blaine, Prietula, \& Pye, 2013), and increases the reader's empathy through simulated social experiences found in fiction and storybooks (Comer Kidd \& Castano, 2013; Mar, Otaley \& Peterson, 2009). Research of the British Cohort Study concluded that frequent reading confers considerable benefits in many subject areas beyond the art of language, significantly in mathematics (Sullivan \& Brown, 2013). There is also evidence that recreational reading enhances community participation (Bus, Van Ijzendoorm \& Pellegrini, 1995) and gives a greater insight into human nature and decision-making (Bruner, 1996).

If recreational reading is important for empowering individuals and communities, it is more so in a volatile, densely populated region such as the Arab world, where the gap of knowledge is widening, and inner conflict is growing. It seems that the subject of recreational reading had not been emphasised for quite a long period in the Arab world, as longitudinal studies documenting Arabs' engagement in and attitudes toward recreational reading did not exist. However, some Arab national studies indicate a major decline in reading across their respective countries, suggesting that a similar decline in reading exists throughout the Arab world. Thus, this study will provide a review of Arab national studies and their reported findings on Arabs' levels of engagement in and attitudes toward recreational reading as well as the availability of resources or presence of home or publicly accessible libraries. In addition, the Arab Reading Index (ARI), which is considered the largest, most significant, and most recent report to investigate Arabs' (students and non-students) frequency of and attitudes toward 'free reading' is thoroughly discussed and its findings reviewed. Other than that, this study examines the Arab reading initiatives that have taken place across the Arab region prior to the release of the ARI, all of which intended to engage younger Arabs in recreational reading are presented.

\section{LITERATURE REVIEW}

Frequent recreational reading habits have shown strong associations for progressive successes in general literary ability (Guthrie, Wigfield, 2000; Moore, Bean, Birdyshaw \& Ryick, 1999; Stanovich, 1986), in addition to explaining positive outcomes in a broader literary sense (Anderson, Wilson \& Fieldiny, 1988; OECD, 2010; Samuels \& Wu, 2003). Regular reading habits have also been shown to nurture the development of vocabulary, word recognition, and the understanding of syntax (Cunningham \& Stanovich, 1998; Samuels \& Wu, 2003; Stanovich, 1986). Research from the British Cohort Study has suggested that regular reading can grant benefits in subject areas in addition to those of language; most notably displaying significant advantages in areas of mathematics (Sullivan \& Brown, 2013). Similarly, the volume of recreational reading conducted outside of school has consistently been found to relate to higher achievement in vocabulary, verbal fluency, reading comprehension, and content knowledge (Krashen, 1993; Short, 1995). 
Recreational reading has additionally been observed to have a positive correspondence with second language competence. Those who read in a second language regularly are bolstering their proficiency for language acquisition (Iftanti, 2012; Krashen, 2004). According to Krashen (1993, p.85), who is a major proponent of the value of reading for pleasure the best children's books contain all the grammar young readers need. Relational to reading content, reading is strongly linked to broader cognitive knowledge, notably in language arts, history, social and scientific studies, in addition to other fields studied in school (Lyon, 1997). Interestingly, high-reading children present a more significant indication of strong vocabulary knowledge than those children with graduated parents (Sullivan \& Brown, 2015). Reading works of fiction has also been found to develop a reader's empathy and extend our understanding of selves by engaging them in a range of simulated social experiences (Comer Kidd \& Castano, 2013; Mar \& Oatley, 2008; Mar, Oatley \& Peterson, 2009).

Young people who read frequently outside of the classroom are 13 times more likely to read above the average age level than their peers who never read outside of the classroom environment (Clark, 2012, p.18). Reading for pleasure can also entice students into discovering other means of reading. If, for example, a student self-discovers personally engaging subject material, a positive attitude toward the overall experience of reading will motivate a positive attitude in favour of general literacy (Booth, 2007). Additionally, self-motivation is imperative in reading development. According to Stanovich (1986), those who are unmotivated are simply unlikely to read. Several international studies suggest that students who are motivated to read fiction (due to enjoyment), are more likely to be better readers than those who read nonfiction, which consequently leads to an improvement in reading comprehension (OECD, 2011). Students who read nonfiction materials, such as magazines, newspapers, and nonfiction publications are shown to possess a greater reading ability, albeit not as marked as the effect of reading fiction books (Baer, Baldi, Ayotte \& Green, 2007; OECD, 2011).

Students who read in their spare or free time ultimately become better readers, score higher on achievement tests in all subject areas, and tend to possess more content knowledge than those who do not (Hughes-Hassell \& Rodge, 2007; Pfost et al., 2010; Anderson et al., 1988; Kim, 2006; Lewis \& Samuels, 2002; Cunningham \& Stanovich, 1998; Krashen, 1993). A study carried out in 2013 found that reading stimulates the part of the brain previously associated with perspective taking and story comprehension (Berns, Blaine, Prietula \& Pye, 2013). Furthermore, frequent reading has been linked to slower cognitive decline (Sullivan \& Brown, 2015), particularly in later life as an activity of cognitive stimulation to ward off the regressive effects of dementia (Vermuri \& Mormino, 2013; Wilson et al., 2013). Regular reading may also offer significant benefits for cognitive resilience, attention, and empathy. Recent research has suggested a link between regular engagement in home literacy practices and reduced likelihood of attention deficit disorder (Froiland \& Davison, 2014). In a broad sense, reading is a window of opportunity for a greater perception of one's self-development, extending to areas of society, economy, and civic engagement (Holden, 2004). Reading, in the words of the British Department for Culture, Media and Sport (DCMS), is "a prerequisite for almost all cultural and social activities". Howard (2011) contends that reading for pleasure contributes vitally toward development in areas of personal values and identity, as well as social engagements and academic performance.

It has been observed that a nation's economic status and progress are bound somewhat to that of its citizens' level of engagement in recreational reading. The OECD (2010a) cited a study (Coulombe et al., 2004) which identified that a nation's reading literacy levels are a 
well-placed previse of economic prosperity and growth. To conclude, recreational reading has a myriad of benefits, which can be categorised into two main sub-sections; literacy-related and personal well-being, to be summarised as follows:

- Improved reading and writing acquisitions (OECD, 2000), incorporating knowledge of grammar and word choice (Cipielewski \& Stanovich, 1992; Cox \& Guthrie, 2001).

- A widened range of vocabulary (Angelos \& McGriff, 2002), and text-deciphering skills (Cunningham \& Stanovich, 1998).

- McKenna \& Kear (1990), found higher achievements in reading abilities, which has been associated with positive attitudes towards reading (Guthrie \& Alvermann, 1999).

- Readers develop in personal growth areas; namely self-confidence (Guthrie \& Alvermann, 1999).

- Readers who continue reading throughout their life report greater satisfaction from reading in their later years (Aarnoutse \& van Leeuwe, 1998).

Of note, the aforementioned literacy-related benefits hold true for both the acquisition of first and second language, in both children and adults (Krashen, 2004). Research has repeatedly presented associations in the frequency and achievement of reading, being that the more one reads, the higher they achieve, and vice versa (Cunningham \& Stanovich, 1998).

- An increased sense of personal well-being (Holden, 2004)

- Diversity in areas of knowledge (Cunningham \& Stanovich, 1998)

- A wider distribution in understanding others' cultures (Meek, 1991).

- A heightened sense of community involvement (Bus, van Ijzendoorm \& Pellegrini, 1995)

- A deeper understanding of decision-making and human motivation (Bruner, 1996).

Reading is one of the important strategies employed by nurses to reduce feelings of loneliness in later-life (Rane-Szostak \& Herth, 1995), and is also shown to foster social skills during childhood (Allan, Ellis \& Pearson, 2005; Clark \& Rumbold, 2006). In conclusion, regular exposure to recreational reading provides the reader with a gateway to experience the true worth and associated enjoyment of reading from many avenues (Sanacore, 2002).

\section{Recreational Reading and the Self}

To begin to understand the complexity of how individuals may develop awareness, interest, and tendency toward recreational reading, an exploration of how the individual self develops during these early and significant stages of life is considered. Martucci (2014) noted that children are active agents in their communicative and learning experiences and that selfengagement in reading storybooks has been found to inspire their quest for reading that further promotes their reading skills. As children learn new skills, introduced by various activities such as reading, their opinions, attitudes, and habits begin to form. In a survey conducted by the National Literacy Trust (NLT) as part of Reading Connects (Clark \& Foster, 2005), most children strongly expressed skills-related reasons for reading; half acknowledged reading to be a valuable and necessary life skill, serving as an aid for the basis of information 
gathering and learning. The third most frequent reason was in terms of reading for enjoyment. When asked specifically about the advantages associated with reading, boys identified with aspects of widening job prospects, girls, on the other hand, preferred reading for personal enjoyment purposes, to learn empathetically from a wide range of fictional scenarios as escapism or break from the norm and to develop personal reading skills. Research conducted by Dungworth et al (2004, cited in Clark \& Rumbold, 2006) reported the most frequently chosen reason for reading was emotional and tended to relate to the way reading made children feel and identified reading for pleasure as a relaxing activity. The findings from both sets of research suggest a strong association for children's reasoning towards reading and their enjoyment is based on the pleasurable experience.

Motivation is formed from positive engagement in reading, during which "the individual's personal goals, values, and beliefs with regard to the topics, processes, and outcomes of reading" (Guthrie \& Wigfield 2000, p. 405) allowing for an increase in reading, leading to an enhancement of reading skills. Thus, encouragement from school programs can indeed be matched with enjoyment and natural skill progression and development of the individual self. While research highlights motivation and frequency for reading achievement as important factors, there is a large array of evidence indicating that older children and adolescents have lesser positive attitudes and motivation for both academic and recreational reading than younger children; furthermore, read less frequently (Eccles,1983; Kush \& Watkins 1996; McKenna et al. 1995; Wigfield et al. 1991). Supportive findings were found in the US Scholastic kids and family reading report (YouGov, 2016), which reported that reading enjoyment was significantly lower among children aged between 12 and 14 years. Prior thought to this, was that children's reading enjoyment has been 'fairly steady' since 2010. Another study found both boys and girls aged 11 tended to choose books that were easier to read (Topping, 2010).

Researchers highlighted a relationship identified between reading attitudes or "feelings related to reading which causes the learner to approach or avoid a reading situation" (Alexander \& Filler, 1976, p1) and reading achievement which appeared to grow stronger with age in junior high school adolescents (Kush et al. 2005). Age does indeed appear to influence the individual's attitude towards reading, and hence the frequency in which one will choose to read; one study revealed that although $30 \%$ of children aged 5-8 were classified as highfrequency readers (reading a book daily) only 17\% of those aged 15-17 read every day (Clark et al., 2008). In summary, during child development and the formation of a sense of self in line with malleable attitudes, behaviours, habits and learning new skills such as reading, frequency, motivation, and age are considerations which have shown to have a connected relationship with and influence on reading for pleasure and the choices that children make.

\section{Personal Empowerment and Sense of Self}

During the early childhood period, children's learning across the various dimensions of development, such as linguistic and emotional, is greater than at any other period but is also highly variable across the dimensions. It also occurs very rapidly, is episodic in nature, and is very susceptible to environmental conditions (Shepard et al. 1998). Based on these observations, we can begin to understand the complexities of early learning and development. The ability to regulate one's thinking and emotions is a product of both innate personal characteristics and the domestic and school environments. Beginning with adolescence, there are numerous aspects of behaviour to consider, among which planning, multitasking, and the 
ability to resist distractions have been identified to take shape during this stage of profound mental change (Blakemore \& Choudhury, 2006). Research has shown that during teenage years, many personal attributes have been acquired (Bronson, 2000), however the capacity to regulate behaviour in achieving long-term goals is somewhat longer, emerging towards the end of adolescence (Demetriou, 2000). Personal choice appears to be a significant factor in developing reading for pleasure. Schraw et al (1998, in Clark \& Rumbold, 2006) observed a positive relationship between choice and affective aspects of reading-such as motivation.

A study carried out by Gambrell, 1996 (cited in Clark \& Rumbold, 2006) found that most children $(80 \%)$ enjoyed the books they had chosen most, compared to those they had not chosen to read. Furthermore, Clark and Phythian-Sence (2008) posit that choice and interest are highly related and integrated; children are more likely to choose books that interest them. Research thus supporting the affective relationship between choice and pleasure towards reading. To affect reading at a behavioural level, however, children and adolescents need to go beyond simply choosing a book; a choice to read a book of interest over partaking in another activity is required. As previously mentioned, resisting distractions - the availability of other recreational activities and an individual's ability to multitask-are components in an adolescent's ever-growing world where reading for pleasure must compete for occupation in daily life. The strength with which attitudes, behaviours, and emerging habits form are dependent on an individual's growing sense of self and stability.

Creativity is one such element of importance during a child's development that appears entwined with the individual sense of self and personal empowerment. For this creativity to be freely expressed, a sense of self-autonomy, worth and independence must be recognised. A child's creative self is formed during the early developmental stage of life, where their environment offers opportunities for a child to express themselves independently, creatively, or fulfilling the perceived desires and expectations of others, more often than not those of parents, and the outcome is one of compliance (Winnicott, 1960). The relationships a child forms with parents, teachers, and society play a pivotal role in the child's sense of freedom in expression; any obstacle experienced or perceived by the child which threatens, blocks, or dictates otherwise, as is the case with authoritarianism, causes a suppression of the creative self.

According to attachment theory, children who enjoy a secure attachment relationship with their parents and caregivers use this relationship a support to venture out and explore their environment (Maccoby et al. 1993). They reach out to others, return to the caregiver for support, and venture out again, going further into the world of social relationships (Ainsworth et al., 1978). Thus, a child surrounded by attitudes and behaviours, not in favour of open creative expression would not be encouraged to develop nor hold outward attitudes of creativity; they would instead lead a life of compliance. More authoritarian parents - who demand obedient, conforming, and dependent offspring - may have children who are never really comfortable exploring the world for themselves. Often, these children fail to develop the ability to relate effectively with others throughout their life (Dorsey \& Forehand, 2003). Reading for pleasure is one such area where a child can be encouraged and influenced by parents, social circles, education, and wider cultural societal habits and attitudes. Winnicott (1960) comments on the existence of the struggle between creativity and compliance that begins in childhood development and later goes on to affect work-life, particularly for those in poverty. Individuals in poverty face circumstances where society sets the requirements of workers - where creativity may not be required - thereby causing suppression of creativity 
in creative individuals and favouring individuals who have already suppressed their creative self in childhood. Both outcomes are not supportive of creative expression and can leave individuals with a sense of dissatisfaction where they are outwardly compliant to work under authoritarian conditions.

To express their creativity, individuals engage in problem-solving and critical thinking to find solutions. Individuals who are not empowered to suggest, discuss, collaborate, or implement their solutions, fail in creative expression. Individuals who are compliant on the other hand, are accepted and flourish in fulfilling the needs of others, in this case, society. The type of task, however, is not likely to be progressive, as reflected in studies that show the dispersion of jobs across countries-which inhibit or accelerate development. Without the early development of creative expression, including activities such as recreational reading, a profound effect of suppressing creativity is notable; compliance withholds an individual's sense of empowerment and self-autonomy. A lack of creative expression-particularly under authoritarianism - is considered a contributing and predictive factor shown to affect recreational activities such as reading for pleasure.

Research studies have indeed found reading attitudes to emerge as the most important factor in explaining variation in reading behaviour (Van Schooten \& de Glopper 2002; Stokmans 2003). Attitudes are formed because of an accumulation of similar, repeated, and reinforcing past experiences. In relation to the social context, reading for pleasure experiences can be accumulated indirectly during social reading time, reading socialisation. In addition, past experiences are also related to cognitive feelings that are present during the reading process and can affect reading attitudes (Mathewson 1994; Ganzeboom et al.1989). For example, if reading is difficult, the reading attitude is susceptible to negative evaluation. Furthermore, the perceived reading proficiency of difficult reading is susceptible to downward adjustment. An individual's personal relationship with reading is malleable and sensitive to both cognitive feelings and social behaviour. The effect of the subjective norm reflects the fact that one's social environment can facilitate or inhibit the behaviour irrespective of the attitude. A further variable thought to be related to attitude and subjective norms are cross-cultural differences (Abrams et al. 1998). Within this framework exists the dimension of individualism-collectivism (cf. Hofstede 2004).

\section{Stability Challenging Social Phenomena Prevalent in The Arab Region}

One of the challenges facing this study was an understanding of the cultural and socioeconomic differences in the Arab region and a distinct lack of long-term research giving consistent, confirming evidence to develop the following discussions. The instability has highlighted the need to describe some of these phenomena as a consideration of this and future studies taking place in the turbulent societies of the Arab region. There is research that shows the specific risks encountered by young children in developing countries compromise their educational development and that the numbers of children affected are highly significant; in some countries, $40-50 \%$ of children under 5 years are somewhat stunted, and there have been conservative estimates that more than 200 million children under 5 years of age in such developing countries are not achieving their potentials in terms of their development (Grantham-McGregor, et al., 2007). The World Bank in its (2016) report presented estimates that more than 143 million Arabs are living in countries experiencing war or occupation and around 17 million have been forcibly displaced from their homes (Xavier, 2016). 
The United Nations Development Programme released the first in a series of Arab Human Development Reports (AHDRs) in 2002 called 'Creating Opportunities for Future Generations', with to engage institutions and citizens in the Arab countries in analysis and discussion about the factors which shape the choices and freedoms available to people across the region. These first reports - produced by a prominent group of independent Arab scholars and researchers - were presented as objective, unbiased examinations of the state of human development in Arab countries and gave a clear indication of the social deficits within and across the region. The (2002) AHD report concluded that while indeed education has made headway among the younger generations, illiteracy has been markedly difficult to eradicate. Therefore, the overall educational achievement among adults in Arab countries remains low on average. Stating the 3 main goals must be towards:

- The acquisition of knowledge;

- Political freedoms; and

- Women's empowerment

The subsequent issues, building a Knowledge Society (AHDR 2003), Towards Freedom in the Arab World (AHDR 2004), Towards the Rise of Women in the Arab World (AHDR 2005), have in turn studied each of the deficits in greater depth, to arrive at a strategic vision of how each deficit is to be overcome in the context of a human development project in the Arab world. Most importantly, the illiteracy rates for the more vulnerable social categories, such as women and the poor, are relatively higher-particularly in the rural areas-where individuals suffer from more intense deprivation of education. Thus, the same differences in literacy follow the same patterns as differences in enrolment in basic education by gender, social status, and locale. It should also be noted that illiteracy among males in Arab countries is not expected to disappear before the end of the first quarter of the twenty-first century, and for women, not until 2040.

In the World Economic Forum's 2014-2015 Global Competitiveness Index, the United Arab Emirates ranked number twelve among the 144 countries surveyed for quality of higher education, whereas Egypt, Libya, and Yemen remained at 119, 126, and 142, respectively. The research literature continues to highlight the weak productivity of education and training systems in the region. An understanding of the complexity of poverty and associated factors provide invaluable knowledge to educators in their efforts to support and teach students who live in poverty. In addition to mobility, other factors examined included health and well-being, language and literacy development, and the availability of material resources. Research carried out in high-poverty, high-performing schools, found that this knowledge does not result in lowered expectations for students living in poverty (Parrett and Budge, 2012).

On the contrary, it leads to empathy and an understanding of the differentiation, development, and support that students need to meet their goals and expectations - as well as clear recognition for their achievements. When children and adolescents are secure in the knowledge that their teachers take an active interest and show an appreciation of the realities of their lives, they become far more inclined to trust and actively engage in learning (Parrett \& Budge, 2012). The research concluded with recommendations to all schools that enrol students who live in poverty should seek to acquire as much understanding as possible about the life circumstances of their students. 
The Arab region has also been subjected to the most rapid increase in war, invasion, and violent conflict among all global regions over the past few decades. Of the factors influencing an individual child's educational prospects in the Arab world, the most important is that of gender and as discussed above, this is more apparent in rural areas. The Arab countriesdespite recent improvement-maintain the characteristic of the world's highest levels of gender disparity in education (Megahed \& Lack, 2011). The most significant reason for this attribute is the generally low status of women throughout the region, which is generally associated with the dominant patriarchal culture (Colclough et al., 2000; Smits, 2007; Moghadam, 2004).

The Middle Eastern countries are part of what has been called the 'patriarchy belt' (Caldwell, 1982), which includes-besides the Arab world-the Asian countries with a Hindu or Confucian background. The form of patriarchy in this region is characterized by patrilocal extended households, where power is in the hands of the senior male, and property, residence, and descend generally proceed through the male line (Moghadam, 2004). As part of this 'classical patriarchal system' (Kandiyoti, 1988), girls are often given into marriage at a relatively early age and are then moved to their husband's household, where they are subordinated to all men and senior women within the household. The major task of women is in producing offspring, and the power they can eventually obtain is through their sons. The main duty of the male figures is to provide income and security. In this culture, there is a strict separation between the male and female domains, with men operating in the public sphere and women in the private. Given the strong emphasis on the male breadwinner role, the high fertility level, and the restriction of women to the private domain, girls' educational attainment and women's employment in the formal economy are very low (Smits, 2007; Spierings et al., 2010).

\section{NATIONAL STUDIES ON ARABS' FREQUENCY OF AND ATTITUDES TOWARDS RECREATIONAL READING}

The following national reports and surveys showed the frequency of and attitudes toward recreational reading across five Arab countries; Tunisia, Algeria, Syria, Palestine, and Saudi Arabia. It is worthwhile to mention that these national studies, some of which as recent as 2015 and 2016, had been conducted before the Arab reading Index was made available. Interestingly, the findings of those studies similarly noted - contrary to the ARI's findingsthat there was a distinct lack of reading among Arabs, and that a culture of reading did not have the foundation in society.

Beginning with Tunisia, a survey which examined the ownership of books at home found that the majority of households (75\%) did not have books at home (Mosaic, 2016). Very few $(18 \%)$ had read a single book in the last year. Of those who had, the results showed that women tend to read marginally more than men. Those aged between 18-25 years read most frequently whilst those between 46-55 years read least often (Mosaic, 2016). Conversely, a study carried out in Palestine found that men read marginally more than women, reporting that more than half the population read, despite a ban imposed on the import of books. The study focused on the presence of libraries at home across families in cities, villages, and campsite areas. The study reported that campsites had the highest number of libraries present, followed by cities and villages. However, reading rates reflected a slight adjustment 
in reading activity, where readers located in cities engaged in recreational reading slightly higher than those located in campsites' (Kaid, 2009).

Comparably, a study published in 2015 in Oran, Algeria stated that Algiers and Constantine, have just 10 libraries for children in their cities, many of which fail to meet the standards set by the Ministry of Culture's General Directorate of Books and Reading. According to the study, an overwhelming majority of schools (93\%) do not have libraries or dedicated reading halls (Bouanaka, 2015). Although the study did not comment on libraries at home across the population, low reading rates and frequency were suggested - particularly among children - to be due to the lack of focus and encouragement in reading in society as a whole (Bouanaka, 2015). Similar findings to the study in Tunisia and Algeria on the presence of libraries in the home and libraries available for children were found in a field study in Latakia, Syria (Kaid, 2009); the majority of families (85\%) do not have libraries for children at home. The 242 families who participated in the study were recognised as living in good educational and financial conditions, suggesting the lack of books was not due to lack of availability or means, however, social attitudes were not reported in the study. Of note, whilst children did not own many books, they read mostly fiction, although the frequency of reading for pleasure was not reported. However, the lack of books available at home implies low levels of engagement in recreational reading.

Returning to the frequency of recreational reading, an article from the Saudi Arabian newspaper Okaz reported individuals to spend on average 6 hours and 48 minutes per week reading, ranking them tenth on the World Culture Score Index and suggesting a considerably higher frequency of reading compared to Tunisia, Palestine, and Algeria (Tashkendi, 2015). It nonetheless, should be noted that the Saudi paper-unlike the previously mentioned studies -included reading religious texts, newspapers, magazines, school textbooks, work files, and entertainment texts. The paper also reported that the majority were reading digital text (Tashkendi, 2015). However, the aforementioned studies above varied in defining recreational reading and age brackets of participants; a noteworthy consideration.

\section{The Arab Reading Index: What it is and its Findings?}

During the second day of the Knowledge Summit that was held in the UAE in December 2016, the results of the Arab Reading Index (ARI) were presented during a discussion on the future of reading in the Arab world. The Arab Reading Index, which is a considerably large quantitative report that investigates Arabs' (students and non-students) levels of engagement and attitudes toward reading, spanned 148,000 individuals from 22 Arab countries, revealing that Arab citizens, on average, read around 17 books, over an average of 35 hours per year. The Index was published in collaboration between the United Nations Development Programme (UNDP) and the Mohammed bin Rashid Al Maktoum Foundation (MBRF) to resolve ambiguity on the realities of reading in the Arab world. Not only did the ARI refute earlier claims that an Arab individual reads an average of a quarter a page per year compared to Western counterparts, but also reported high levels of engagement in recreational reading, challenging mostly all previous studies conducted in the field of recreational reading in the Arab region.

The results showed that the average Arab spends 35 hours reading, of which 20 hours are in academic institutions and 15 hours outside, with more than half of this reading, carried out on electronic platforms. On average, 11 Arabic books and 6 foreign-language books are 
read each year. The index showed the accessibility to reading materials in each country at home, academic institutions, and overall society, revealing how society - in particular families and school administrations - has witnessed an improvement in facilitating and motivating reading throughout the Arab world. With society being the least encouraging, only $37 \%$ of individuals agreed that society encourages their reading, whereas $46 \%$ claimed they had access to reading materials at home and 52\% agreed that their school provides the facilities required for reading. The ability to read (presented as the literacy rate), motives to read, and personal views and opinions were also examined to demonstrate to what extent personal skills have on one's personal reading habits. The results showed that $70 \%$ of respondents agreed that reading is an essential activity, and 65\% considered reading as a necessity. At the top of the index was Lebanon, with an overall score of 90 out of 100, followed by Egypt with 89 , Morocco with 87, the UAE with 82, and Jordan 71. The figure below illustrates the average reading hours and the books read per year in each of the Arab countries.

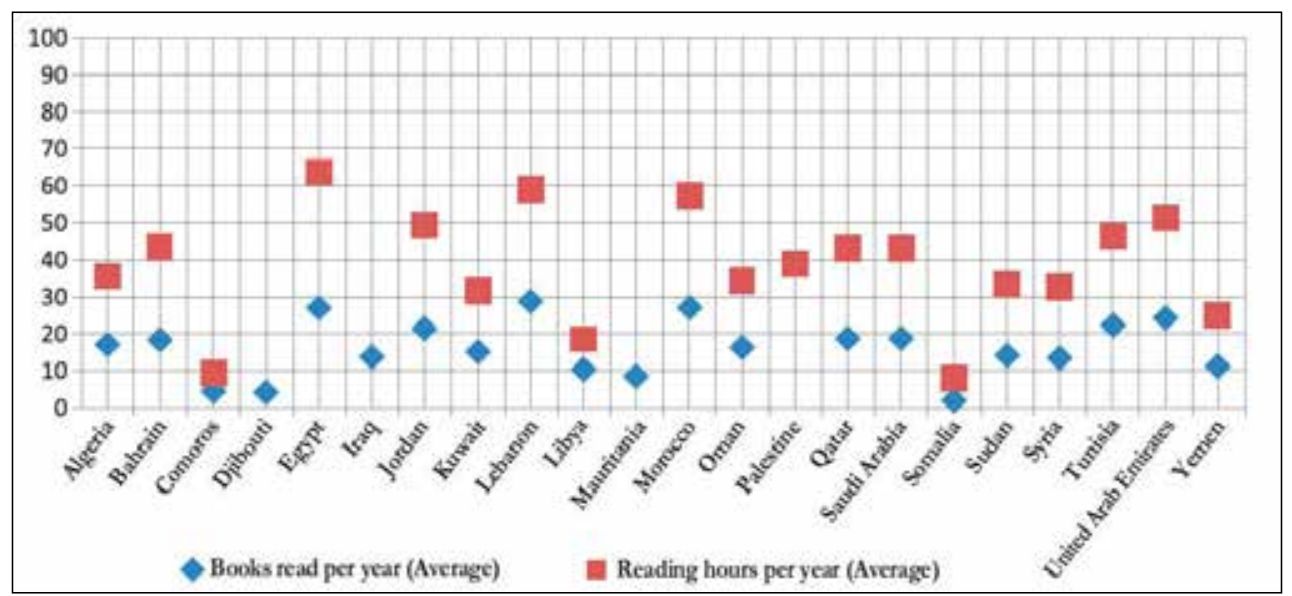

Figure 1 The average reading hours and books read per year in each of the Arab countries. Adapted from the Arab Reading Index (Source: MBRF\& UNDP/RBAS, 2016, p.16).

Participant's preferences of the reading format were also analysed during the survey to identify the mediums that readers generally expose themselves to. The report showed that readers continue to use printed materials, where nonfiction books ranked first $(28.05 \%)$, followed by fiction books (20.55\%), and specialist magazines $(20.21 \%)$. The two lowest reading mediums proved to be newspapers and comics (17.06\% and $14.21 \%$ respectively). These results show that at $48.6 \%$, books are the predominant medium of reading for Arabs among the variations of printed material. The report also analysed the reading habits for preferences of electronic formats, presenting figures for reading material on social media $(23.52 \%)$, closely followed by news websites (23.02\%), e-book applications (21.01\%), e-magazines (15.32\%), and lastly blogs and professional networks (9.35\% and $7.78 \%$ respectively), showing that most online reading is associated with social life and current affairs.

In order to instill reading as a habit among youth's daily activities, many considerations need to be taken into account. One of these considerations is the significant role that the social environment plays in promoting students' engagement in recreational reading. The Arab Reading Index in its survey included questions that related to the role of prominent social agents, particularly the role of family, social institutions, and wider society. These sections 
represent the findings of the ARI on the aforementioned social agents. Note that the source of the information given in section 2.4 and its subsections is the Arab reading Index (MBRF, UNDP/BRAS, 2016).

\section{Family}

The ARI recognises the complexity in understanding an individual's antipathy towards reading; describing illiteracy, ignorance, poverty, unemployment-among many-as contributing factors. It is also recognised, however, that an intimate and enjoyable relationship with books as well as the promotion of a reading culture provided within, by the family, has the ability to significantly challenge these influences. Therefore, a child's first encounter with books in the Arab world is often a prosaic experience, with the mandatory reading of textbooks in an institutional school environment-which promotes a listless initial response toward reading activities. A large disparity - 1.45 in Somalia and 94.84 in Lebanon - between the scores on the family sub-pillar explains the low overall score. In the upper ranges, eleven countries scored over 50, including 4 countries with scores over 80 (Egypt, Lebanon, Morocco, and UAE), five countries that scored between 60 and 75 (Bahrain, Jordan, Qatar, Saudi Arabia, and Tunisia), and two countries (Algeria and State of Palestine) that scored almost 50 . In the lower ranges, Comoros, Djibouti, Libya, Mauritania, Somalia, and Yemen scored below 20. Where this study identified a positive correlation between reading habits and other familyoriented variables - including the parent's level of education and frequency of reading, and the access to reading materials at home-all relevant studies have confirmed a strong positive correlation between the family environment and the child's attraction towards reading.

\section{Educational Institutions}

With a similar approach to family influences, educational institutions provide multiple opportunities to introduce and maintain attitudes towards reading to the child. In Arab countries, it is likely that the school environment is the first encounter of the practical application of books, where there is an overlap of learning to read and the perceived pleasure of reading. This pivotal first impression should shape the ongoing attitudes of the child toward the experience of reading for enjoyment. Acknowledging the fragility of this developmental stage is a key consideration in the education strategy and the design of school facilities, curricula, and administration. As would be expected, scores on the educational sub-pillar closely followed the individual country performance for the family sub-pillar; the range was polarised by Somalia (7.44) and Morocco (93.6) with a central tendency around that of 52. Promisingly Algeria, Kuwait, Oman, and the State of Palestine joined the above-average countries in the family scores to form the upper ranges. The remaining countries collectively represent the lower range with Comoros, Djibouti, Libya, and Somalia obtaining scores under 20. The ARI states that these results indicate the availability of suitable environments for creating reading communities and suggests the responsibility of schools to positively inculcate such reading habits in a manner that is enjoyable and able to influence participation of reading activities outside of guided instruction.

\section{Society}

Taking into account the reading opportunities provided by ministries and civil society organizations to encourage reading and strengthen young people's relationships with books, the ARI stipulates that in countries where reading activities are significant, there can be seen considerable effort outside of the family and educational environments to support and 
encourage reading activities and promote the results that such activities may yield, as well as provide the necessary facilities associated with access and availability. In contrast to the previous two sub-pillars, with results that ranged from extremes of 1.67 in the case of Somalia, and 75.92 seen in the United Arab Emirates, the overall scores produced a lower medium of 36.56 across all countries. The ARI suggested a relation to the weak cultural environment in some Arab countries to the low access in reading opportunities in both government and private institutions that represent the society level. The index further suggested that in order to help overcome the intellectual and knowledge deficits that lie at the heart of the cultural, civilizational, scientific, and technological challenges facing the Arab world, a need exists to consider the formulation of strategic plans by all role players, where the primary concern is the education and development of children-including families; ministries of culture, education and youth affairs; media outlets; and civil society institutions - in order to direct efforts at encouraging children that regular reading results in recognised and rewarded gains.

\section{Access and Availability}

All tiers of social influence-domestic (family), educational and wider society contribute to the individual's engagement that develops their behavioural habits. The inculcation of reading activity is therefore entirely dependent on the presence of actual reading material and visual reading activity in the child's immediate environment. The Access and Availability pillar assesses the existence of an enabling and encouraging environment for reading across the studied Arab countries. In the Reading Index's Access and Availability pillar, the focus was given to the youth's immediate family environment, the supportive educational institutions, and the wider society, summing their overall influences as a whole throughout the Arab region. The countries which were shown to provide the greatest enabling environmentobtaining an overall score upwards of 80-were Morocco, UAE, Egypt, and Lebanon, while the lowest scoring of this pillar came from Djibouti, Comoros, and Somalia, each obtaining scores below that of 10, portraying very little support. The types of reading access recorded in the results presented an interesting variance between and within each of the countries and are shown in the figure below.

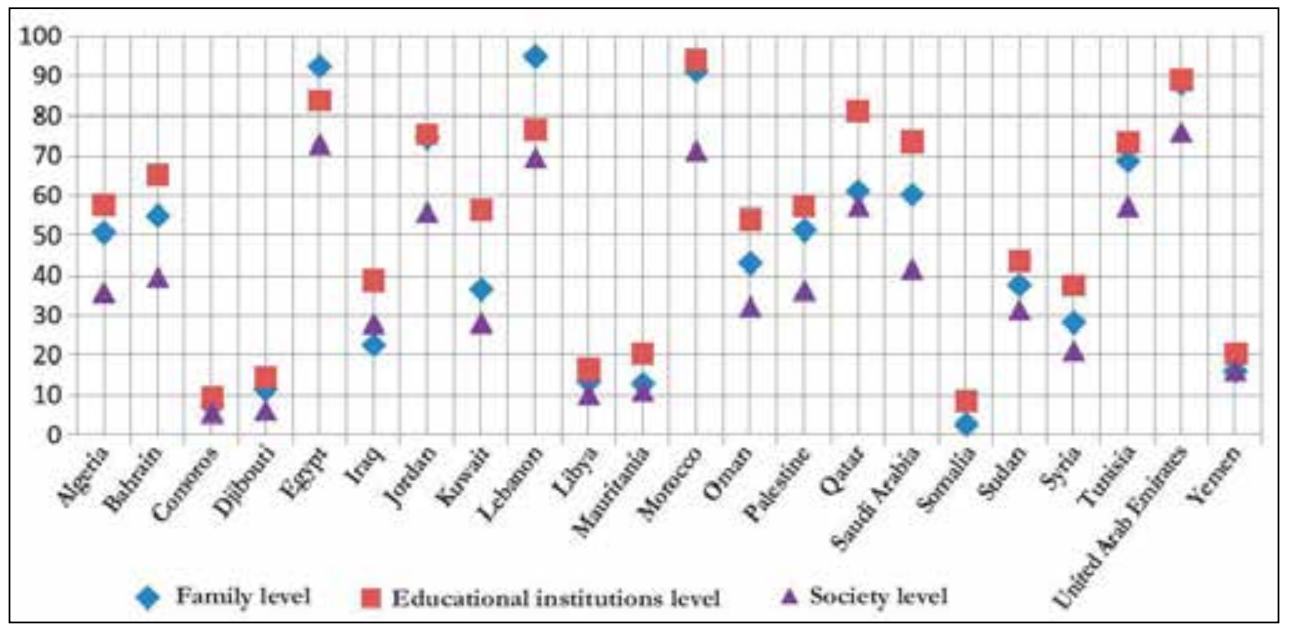

Figure 2 Access and availability sub-pillars: Results of Arab countries. (Source: Adapted from the Arab Reading Index MBRF\& UNDP/RBAS, 2016, p.2). 


\section{Reading: Comfort and Happiness}

The ARI questionnaire asked respondents if their reading activities were related to personal positive emotions, such as a feeling of joy or happiness and $64.93 \%$ confirmed that this correlation was correct from their viewpoint - an opinion that was shared by most participants in every country included in the survey. The ARI then divided the individual countries into one of three groups based on overall performance. The first group consisted of countries where more than $70 \%$ of participants identified a positive correlation to reading and happiness, including Egypt, Lebanon, Morocco, and the United Arab Emirates. The second group was arranged by countries scoring between $60 \%$ and $70 \%$, these are Algeria, Bahrain, Iraq, Jordan, Kuwait, Oman, State of Palestine, Qatar, Saudi Arabia, Sudan, Syria, Tunisia, and Yemen. Finally, in the lower portion were: Comoros, Djibouti, Libya, Mauritania, and Somalia whose results averaged between $50 \%$ and $60 \%$ overall. Participants were then asked to identify the main reason why they read and were given eight possible options to choose from. Of the options, the top four chosen were: looking for information; the joy of reading itself; curiosity; and to acquire wider knowledge. The lower scoring options were: at the request of parents or teachers; self-development; and improving one's level of knowledge. The report went on to explain that the most common motives for reading in Arab countries combine an external motive in terms of knowledge acquisition or education and an internal motive based on personal enjoyment and satisfying curiosity. The diagram below shows the most frequent motives for people's engagement in reading.

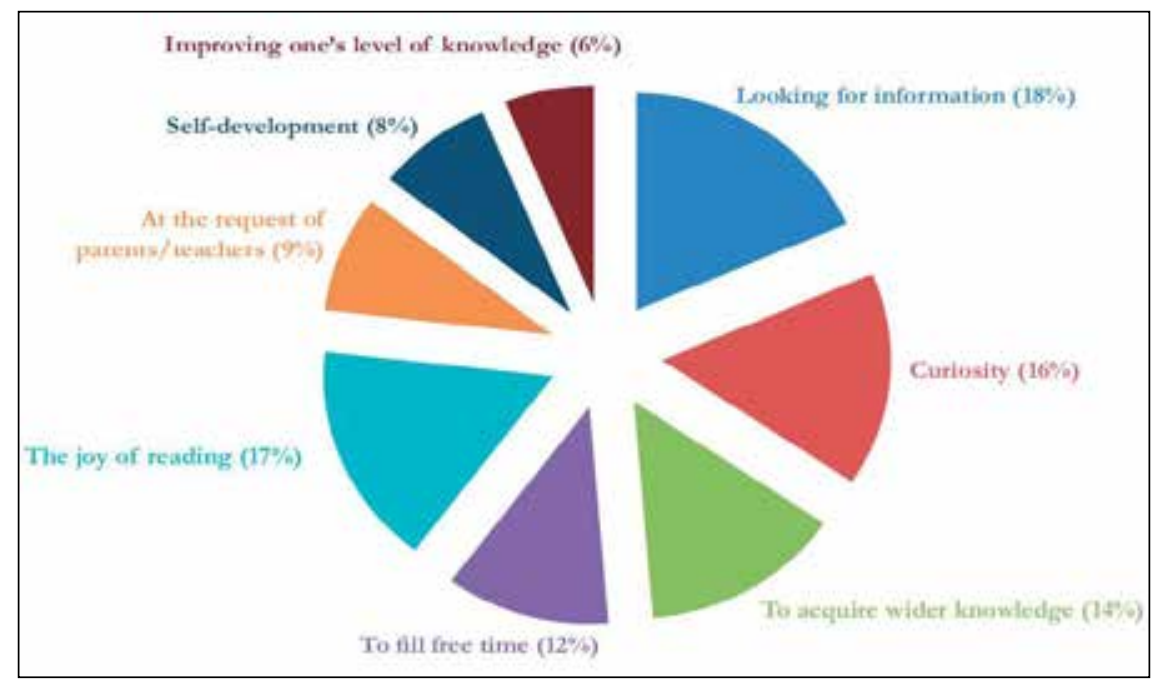

Figure 3 Motives for reading across the Arab region.

(Source: Adapted from the Arab Reading Index - MBRF\& UNDP/RBAS, 2016, p.26).

\section{Types of Printed Material Respondents Read}

The ARI asked participants to note their favoured printed reading materials to understand how the mediums were fairing in an era of shifting towards technological inquiry. Optimistically, the report found that books retained their importance for those inclined to read. nonfiction material scored highest at $28.05 \%$, followed by fiction at $20.55 \%$, slightly above that of specialized magazines (20.21\%). Periodicals, such as newspapers and comics 
held a less important rank at $17.06 \%$ and $14.12 \%$ respectively. These rankings were seen in all Arab countries - apart from Somalia, which ranked fiction equal to nonfiction. The combined scores of fiction and nonfiction preferences show that a total of $48.6 \%$ of the participants asked hold preference to printed books when choosing their reading materials. The figure below shows the types of printed material respondents read across the Arab world.

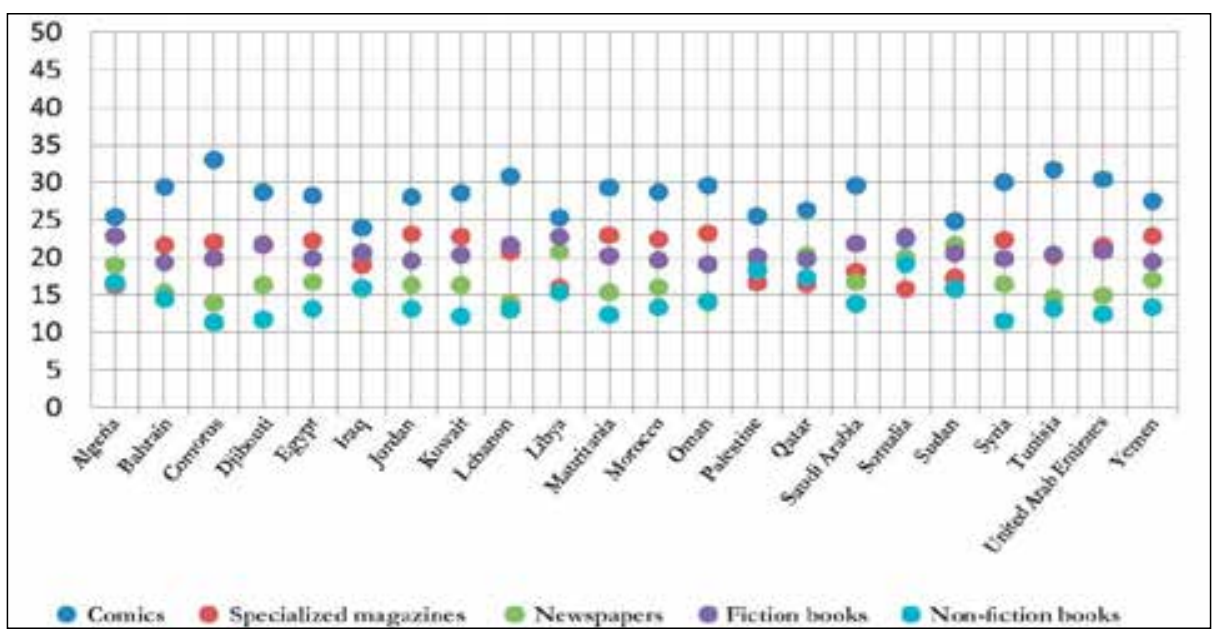

Figure 4 Types of Printed Material Respondents Read. (Source: Adapted from the Arab Reading Index - MBRF\& UNDP/RBAS, 2016, p.26).

\section{Types of Electronic Material Respondents Read}

With more than half the world's population now on the internet (Digital in 2017 Global Overview Report) the ARI considered electronic material as a substantial make-up of recreational reading. The results of the survey showed that most respondents chose social media as their primary preferred source of electronic content (23.52 percent), with many also viewing content by news media (23.02 percent), and those who engaged in electronic or e-books (21.01 percent). There was a smaller representation of those attracted to specialised magazine content (15.32 percent), and finally, those who sought out content on blogs and professional networks (9.35 and 7.78 percent respectively). The ARI concluded that the motivation towards electronic content centred on a connection to a person's wider public network and agreed with the Next Page Foundation that most people who use the internet do so to socialise and read current affairs. (100 percent in Syria, 80 percent in Lebanon, 78 percent in the State of Palestine, 77 percent in Saudi Arabia, 75 percent in Jordan, 62 percent in Egypt, 59 percent in Morocco, and 55 percent in Tunisia). 


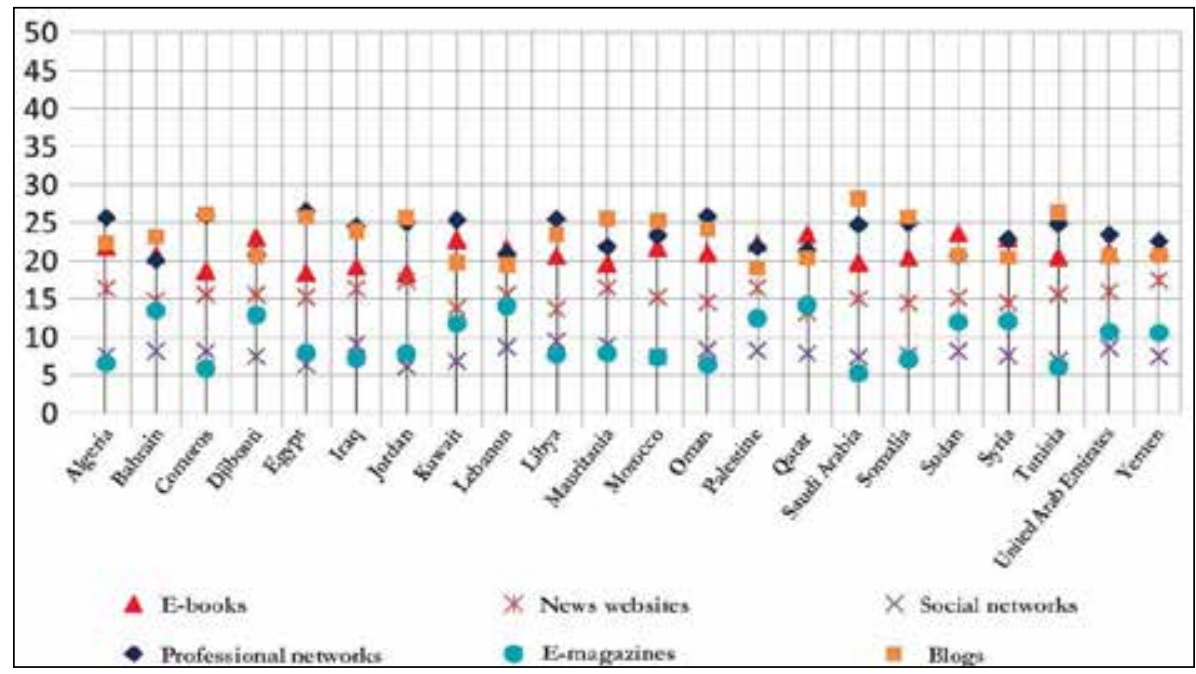

Figure 5 Types of Printed Material Respondents Read. (Source: Adapted from the Arab Reading Index (MBRF\& UNDP/RBAS, 2016, p.26).

\section{CONCLUSION}

As the national reports and surveys found there is a distinct lack of reading among Arabs, and that a culture of reading, especially for pleasure did not have the foundation in society. Some of this could be accredited to the lack of access to books, especially in Algeria, Tunisia, and Syria be it in the home or a library that children could access. Contrary to these reports and surveys however was the Arab Reading Index (ARI), this study looked at a much broader audience than the national reports and surveys and found that Arabs were reading much more than previously thought. However, the ARI considered electronic material, and materials that are used in academia, this could be why it is more in line with the Saudi Arabian newspaper, Okaz.

Another noteworthy analytic of the ARI is that it found that print media was still an extremely popular medium, and of the printed media $20.55 \%$ read was fiction, if we consider the importance on a child's development based on fiction and how that is stronger than that of nonfiction (OECD, 2011), we can deduce that more needs to be done to encourage this number to rise. The importance here could be on the family, rather than educational institutions, as often a child's first experience of reading is in an institutional school which often promotes a listless response. If, however the child was introduced to a fictional book earlier which could promote a desire to grow further and develop faster.

Looking more specifically at recreational reading in the Arab within the context of the ARI, $17 \%$ of respondents said they read for the joy of reading, $12 \%$ of these are the children who would be most likely to pick up a book for fun and continue if we combine this with the fact that $20.55 \%$ of books read are fiction, we can draw that while this is a good step for the development of children in the Arab world, more could be done. However, before it can be done the biggest factors that affect a child's desire need to be addressed, these being access to materials, as well as society's view on reading. It could be worth a study looking 
into how changing the societal views on reading could change the reading level in children in the Arab world, coupled with the encouragement of the family in the development of a child's reading progress.

\section{REFERENCES}

Aarnoutse, C. \& van Leeuwe, J. (1998). Relation between reading comprehension, vocabulary, reading pleasure and reading frequency. Educational Research and Evaluation, 4, 143-166. Retrieved on January 2018 from http://www.tandfonline.com/doi/abs/10.1076/ edre.4.2.143.6960

Abrams, D., Ando, K., \& Hinkle, S. (1998). Psychological attachment to the group: Crosscultural differences in organizational identification and subjective norms as predictors of workers' turnover intentions. Personality and Social psychology bulletin, 24(10), 1027-1039.

Ainsworth, M. D. S., Blehar, M. C., Waters, E., \& Wall, S. (1978). Patterns of attachment: A psychological study of the strange situation. Lawrence Erlbaum Associates. NY, USA

Alexander, J. E., \& Filler, R. C. (1976). Attitudes and reading. Newark, Del.: International Reading Association. Retrieved from https://eric.ed.gov/?id=ED126491

Allan, J., Ellis, S. \& Pearson, C. (2005). Literature circles, gender and reading for enjoyment. Edinburgh: Scottish Executive. Scotland.

Anderson, R., Wilson, P., \& Fielding, L. (1988). Growth in reading and how children spend their time outside of school. Reading Research Quarterly, 23(3), 285-303.

Angelos, S., \& McGriff, N. (2002). Tracking students' reading progress. Knowledge Quest, 30(5), 44-46. Retrieved from https://eric.ed.gov/?id=EJ652527

APTER, M.J. (1979). Human action and theory of psychological reversals. In G. Underwood \& R. Stevens (Eds.), Aspects of Consciousness (Vol. 1). London: Academic Press. London, UK.

Baer, J., Baldi, S., Ayotte, K., \& Green, P. (2007). The reading literacy of U.S. fourth-grade students in an international context: Results from the 2001 and 2006 Progress in International Reading Literacy Study (PIRLS). National Center for Education Statistics, Institute of Education Sciences, U.S. Department of Education. Washington DC, USA.

Berns, G. S., Blaine, K., Prietula, M. J., \& Pye, B. E. (2013). Short and long-term effects of a novel on connectivity in the brain. Brain Connectivity, 3(6), 590-600. Retrieved from https://doi.org/10.1089/brain.2013.0166

Blakemore,S. J. \& Choudhury, S. (2006). Development of the adolescent brain: implications for executive function and social cognition. Journal of Child Psychology and Psychiatry, 47(3-4), 296-312. Retrieved from https://doi.org/10.1111/j.1469-7610.2006.01611.x

Booth, H. (2007). Serving teens through readers' advisory. American Library Association, Chicago, IL, USA.

Bouanaka, S. (2015). Reading venues available for Algerian children. Cybrarians Journal, 38. June 2015. Retrieved on September 23, 2016 from: http//: www.journal.cybrarians. org/index.php?option=com_content\&view=article\&id:693=souad\&catid=:275r esearches\&Itemid93=

Bronson, M. B. (2000). Self-regulation in early childhood: Nature and nurture. Guilford Press. NY, USA.

Bruner, J. (1996). The culture of education. Cambridge, MA: Harvard University Press. USA. 
Bus, A.G., van Ijzendoorm, M.H., \& Pellegrini, A.D. (1995). Joint book reading makes for success in learning to read: A meta-analysis on intergenerational transmission of literacy. Review of Educational Research, 65(1), 1-21.

Caldwell, L. (2012, January 10). The Arab reader and the myth of six minutes. Al Akhbar. Retrieved September 23, 2016, from: http://english.alakhbar.com/node/3168

Cipielewski, J., \& Stanovich, K. E. (1992). Predicting growth in reading ability from children's exposure to print. Journal of Experimental Child Psychology, 54(1), 74-89.

Clark, C. (2012). Children's and young people's reading today. Findings from the 2011 National Literacy Trust's annual survey. London: National Literacy Trust. London, UK.

Clark, C., \& Rumbold, K. (2006). Reading for pleasure: A research overview. London: National Literacy Trust. London, UK.

Clark, C., Osborne, S., \& Akerman, R. (2008). Young people's self-perceptions as readers: An investigation including family, peer and school influences. National Literacy Trust (NLT). London, UK.

Clark, C. \& Foster, A. (2005). Children's and young people's reading habits and preferences the who, what, why, where and when. London: National Literacy Trust (NLT).

Clark, C. \& Phythian-Sence, C. (2008). Interesting choice the (relative) importance of choice and interest in reader engagement. London: National Literacy Trust (NLT).

Comer Kidd, D. \& Castano, E. (2013). Reading literary fiction improves theory of mind. Science, 342, 377-380.

Coulombe, S., Tremblay, J.-Ff. and Marchand, S. (2004). Literacy scores, human capital and growth across fourteen OECD countries. Ottawa: Statistics Canada.

Cox, K. E., \& Guthrie, J. T. (2001). Motivational and cognitive contributions to students' amount of reading. Contemporary Educational Psychology, 26 (1), 116-131.

Colclough, C., Rose, P., \& Tembon, M. (2000). Gender inequalities in primary schooling: The roles of poverty and adverse cultural practice. International Journal of Educational Development, 20 (1), 5-27. Brighton, UK.

Cullinan, B. (2000). Independent reading and school achievement. New York: New York University.

Cunningham, A., \& Stanovich, K. (1998). What reading does for the mind. American Educator, 22 (1-2), 8-15.

DCMS (2003). Framework for the Future: Libraries, learning and information in the next decade. London: Department for Culture, Media and Sport.

Demetriou, A. (2000). Organization and development of self-understanding and selfregulation: Toward a general theory. In M. Boekaerts, P. R. Pintrich, \& M. Zeidner (Eds.), Handbook of self-regulation (pp. 209-251). London: Academic Press.

Dungworth, N., Grimshaw, S., McKnight, C. \& Morris, A. (2004). Reading for pleasure? A summary of the findings from a survey of the reading habits of year 5 pupils. New Review of Children's Literature and Librarianship, 10, 169-188.

Dorsey, S., \& Forehand, R. (2003). The relation of social capital to child psychosocial adjustment difficulties: The role of positive parenting and neighborhood dangerousness. Journal of Psychopathology and Behavioral Assessment, 25 (1), 11-23.

Eccles, J. S. (1983). Expectancies, values, and academic behaviors. Goethe Universitat. Retrieved from https://publikationen.ub.uni-frankfurt.de/frontdoor/index/index/ docId/12327 
Froiland, J. M., \& Davison, M. L. (2014). Home literacy, television viewing, fidgeting and ADHD in young children. Educational Psychology. 1-17. doi: 10.1080/01443410.2014.963031

Gambrell, L.B. (1996). Creating classroom cultures that foster reading motivation. The Reading Teacher, 50, 14-25.

Ganzeboom, H. B., Luijkx, R., \& Treiman, D. J. (1989). Intergenerational class mobility in comparative perspective. Research in social Stratification and Mobility, 8, 3-79.

Grantham-McGregor, S., Cheung, Y. B., Cueto, S., Glewwe, P., Richter, L., Strupp, B., \& International Child Development Steering Group. (2007). Developmental potential in the first 5 years for children in developing countries. The lancet, 369 (9555), 60-70. doi: 10.1016/S0140-6736(07)60032-4

Guthrie, J. T., Wigfield, A., \& VonSecker, C. (2000). Effects of integrated instruction on motivation and strategy use in reading. Journal of Educational Psychology, 92 (2), 331-341.

Guthrie, J.T. \& Alvermann, D. E. (1999). Engaged reading: Processes, practices, and policy implications. New York: Teachers College Press.

Hofstede, G., \& McCrae, R. R. (2004). Personality and culture revisited: Linking traits and dimensions of culture. Cross-cultural research, 38 (1), 52-88.

Holden, J. (2004). Creative reading: Young people, reading and public libraries. London: Demos.

Howard, V. (2011). The importance of pleasure reading in the lives of young teens: selfidentification, self-construction and self-awareness. Journal of Librarianship and Information Science, 43, 46-55. doi: 10.1177/0961000610390992

Hughes-Hassell, S., \& Rodge, P. (2007). The leisure reading habits of urban adolescents. Journal of Adolescent $\mathcal{E}$ Adult Literacy, 51 (1), 22-33.

Kandiyoti, D. (1988). Bargaining with patriarch. Gender E Society, 2(3), 274-290.

Kaid, S. (2009). Reading is key to culture: Its concept and role in individual and community development. Afnan Cultural Salon. Retrieved on September 23, 2016 from: http//: www. afnanculturalsalon.org/salon_kalimat.74/htm

Kim, J.S. (2006), Effects of a voluntary summer reading intervention on reading achievement: results from a randomized field trial. Educational Evaluation and Policy Analysis, 28, 335-355.

Krashen, S. (2004), Free voluntary reading: new research, applications, and controversies. Paper presented at the Pan-Asian Conference, Vladivostock, Russia.

Krashen, S. D. (1993). The case for free voluntary reading. Canadian Modern Language Review, 50 (1), 72-82.

Kush, J. C., \& Watkins, M. W. (1996). Long-term stability of children's attitudes toward reading. The Journal of Educational Research, 89 (5), 315-319.

Kush, J. C., Watkins, M. W., \& Brookhart, S. M. (2005). The temporal-interactive influence of reading achievement and reading attitude. Educational Research and Evaluation, 11(1), 29-44.

Lewis, M. (2002). Read More-Read Better? A Meta-Analysis of the Literature on the Relationship Between Exposure to Reading and Reading Achievement, PhD Thesis. University of Minnesota, Minneapolis, USA.

Lyon, G. R. (1997). Measuring Success: using assessments and accountability to raise student achievement. ProjectPro. Retrieved from http://projectpro.com/ICR/Research/Releases/ NICHD_Testimony1.htm 
Maccoby, E. E., Buchanan, C. M., Mnookin, R. H., \& Dornbusch, S. M. (1993). Postdivorce roles of mothers and fathers in the lives of their children. Journal of Family Psychology, 7(1), 24-38.

Mar, R. A. \& Oatley, K. (2008). The function of fiction is the abstraction and simulation of social experience. Perspectives on Psychological Science, 3(3), 173-192.

Mar, R., Oatley, K. \& Peterson, J. (2009). Exploring the link between reading fiction and empathy: Ruling out individual differences and examining outcomes. Communications, 34 (4), 407-428.

Martucci, K. (2014). Shared storybook reading in the preschool setting and considerations for young children's theory of mind development. Journal of Early Childhood Research, 14 (1), 55-68.

Mathewson, G. C. (1994). Model of attitude influence upon reading and learning to read. In R. B. Ruddell, M. R. Ruddell, \& H. Singer (Eds.), Theoretical models and processes of reading (p. 1131-1161). Newark: International Reading Association

McKenna, M., Kear, D., \& Ellsworth, R. (1995). Children's Attitudes toward Reading: A National Survey. Reading Research Quarterly, 30 (4), 934-956.

Meek, M. (1991). On being literate. New Statesman and Society, 4, 34-34.

Megahed, N., \& Lack, S. (2011). Colonial legacy, women's rights and gender-educational inequality in the Arab World with particular reference to Egypt and Tunisia. International review of Education, 57 (3-4), 397-418.

Moghadam, V. (2004). Patriarchy in Transition: Women and the Changing Family in the Middle East. Journal of Comparative Family Studies, 35(2), 137-162.

Moore, D. W., Bean, T. W., Birdyshaw, D., \& Rycik, J. A. (1999). Adolescent literacy: A position statement. Journal of Adolescent $\mathcal{E}$ Adult Literacy, 43(1), 97-112.

Nell, V. (1988). The psychology of reading for pleasure: Needs and gratifications. Reading Research Quarterly, 21 (1), 6-50.

OECD (2002). Reading for change: Performance and engagement across countries: Results from PISA 2000. New York: Organisation for Economic Cooperation and Development

OECD (2010a), PISA 2009 Assessment framework: Key competencies in reading, mathematics and science. France: OECD Publishing.

OECD. (2002). Knowledge and Skills for L ife: First Results from PISA 2000. Paris: OECD Publishing

OECD. (2011a). Do students today read for pleasure? Pisa in Focus (Vol.8). Washington, D.C.: OECD Publishing.

OECD. (2011b). Education at a glance. Washington, D.C.: OECD Publishing.

Parrett, W. \& Budge, K, (2012). Turning high-poverty schools into high-performing schools. Virginia: ASCD.

Pfost, M., Dorfler, T. and Artelt, C. (2010). The relation between extra-curricular reading behavior and reading competence: results from a longitudinal study at the transition from primary to secondary school. Zeitschrift Fur Entwicklungspsychologie Und Pädagogische Psychologie, 42, 167-176.

PISA (2010). Results: What students know and can do-student performance in reading, mathematics and science (Volume I). Paris: Organisation for Economic Cooperation and Development. 
Radio Mosaic (2016, March 30). Survey: Tunisians do not read books. Retrieved on November 4, 2016 from: http://www.mosaiquefm.net/ar/

Rane-Szostak, D. \& Herth, K. (1995). Pleasure reading, other activities, and loneliness in later life. Journal of Adolescent \& Adult Literacy, 39, 100-108.

Richardson, P. W., \& Eccles, J. S. (2007). Rewards of reading: Toward the development of possible selves and identities. International Journal of Educational Research, 46 (6), 341-356.

Robinson, P. (2000). The news media and intervention: triggering the use of air power during humanitarian crises. European Journal of Communication, 15 (3), 405-414.

Samuels, S. J., \& Wu, Y. C. (2003). How the amount of time spent on reading effects

reading achievement: A response to the National Reading Panel. Minneapolis, MN: University of Minnesota. USA.

Sanacore, J. (2002). Struggling literacy learners benefit from lifetime literacy efforts. Reading Psychology, 23, 67-86.

Schraw, G., Flowerday, T., \& Reisetter, M. F. (1998). The role of choice in reader engagement. Journal of Educational Psychology, 90(4), 705-714.

Shepard, L. A., Kagan, S. L., \& Wurtz, E. (Eds.). (1998). Principles and recommendations for early childhood assessments. Washington, DC: National Goals Panel.

Smits, J. P. J. M. (2007). Family background and context effects on educational participation in five Arab countries. HK. Nijmegen, The Netherlands.

Spierings, N., Smits, J., \& Verloo, M. (2010). Micro- and macrolevel determinants of women's employment in six Arab countries. Journal of Marriage and Family, 72(5), 1391-1407.

Stanovich, K. E. (1986). Matthew effects in reading: Some consequences of individual differences in the acquisition of literacy. Reading Research Quarterly, 22, 360-407.

Stokmans, M. J. (2003). How heterogeneity in cultural tastes is captured by psychological factors: a study of reading fiction. Poetics, 31(5-6), 423-439.

Sullivan, A., \& Brown, M. (2013). Social inequalities in cognitive scores at age 16: The role of reading. CLS Working Papers, 2013 (13/10). Retrieved from http://discovery.ucl. ac.uk/id/eprint/1473708

Sullivan, A., \& Brown, M. (2015). Reading for pleasure and progress in vocabulary and mathematics. British Educational Research Journal, 41(6), 971-991.

Tashkendi, K.A. (2015). Fears of a Cultural Desertification ... Is it True that Arabs do not Read? Okaz website. January 7, 2015. Retrieved on September 23, 2016 from: http//:www. okaz.com.sa/new/Issues/20150107/Con20150107745479.htm

Topping K. J. (2010). Methodological quandaries in studying process and outcomes in peer assessment. Learning and Instruction, 20, 339-343.

Van Schooten, E., \& de Glopper, K. (2002). Poetics, 30(3), 169-194

Vermuri, P. \& Mormino, E. C. (2013). Cognitively stimulating activities to keep dementia at bay. Neurology, 81 (4), 308-309.

Wigfield, A., Eccles, J. S., Mac Iver, D., Reuman, D. A., \& Midgley, C. (1991). Transitions during early adolescence: Changes in children's domain-specific self-perceptions and general self-esteem across the transition to junior high school. Developmental Psychology, $27(4), 552-565$ 
Wilson, R. S., Boyle, P. A., Yu, L., Barnes, L. L., Schneider, J. A. \& Bennett, D. A. (2013). Lifespan cognitive activity, neuropathologic burden, and cognitive aging. Neurology, 81(4), 314-321.

Winnicott, D. W. (1962). The theory of the parent-infant relationship-further remarks. International Journal of Psycho-Analysis, 43, 238-239.

YouGov. (2016). Kids and family reading report. USA: Scholastic.

Xavier, D. (2016). Forcibly displaced: toward a development approach that supporting refugees, the internally displaced, and their hosts. Washington, DC: The World Bank Group 